\title{
In vitro Metabolism of Risperidone on Isolated Microsomes of Rat Liver: Metabolite Identification and Profiling by RP-HPLC and LC-MS Techniques
}

\author{
Prutha Shirodkar ${ }^{1, *}$, Harshal Chavan², Rajendra Mogal ${ }^{3}$, Avinash Dhake $^{1}$ \\ 1Department of Pharmaceutical Chemistry, S.M.B.T. College of Pharmacy, Nashik, Maharashtra, INDIA. \\ 2Department of Pharmaceutical Chemistry, Sandip Foundation's, Sandip Institute of Pharmaceutical Sciences, Nashik, Maharashtra, \\ INDIA. \\ ${ }^{3}$ Department of Pharmaceutics, Sandip Foundation's, Sandip Institute of Pharmaceutical Sciences, Nashik, Maharashtra, INDIA.
}

\begin{abstract}
Objective: The objective of present research work is to study in vitro metabolism of risperidone on isolated microsomes of rat liver. Methods: Its biotransformation was examined using isolated microsomes derived from rat livers. Their separation was accomplished on Jasco RP-HPLC C-18 column (250mm $\times 4.6 \mathrm{~mm} \times 5 \mu \mathrm{m}$ ) using methanol: $50 \mathrm{mM}$ Potassium dihydrogen phosphate $(50: 50 \% \mathrm{v} / \mathrm{v})$ mobile phase, detected at a wavelength of $280 \mathrm{~nm}$. Results: In vitro metabolism of RIS was investigated using the cytochrome P450 (CYP450) enzymes supplemented with an NADPH- generating system. Incubation of RIS with rat liver microsomes resulted in the formation of 2 major hydroxy metabolites. Conclusion: Formation of all the metabolites is correlated with Phase I biotransformation CYP enzyme subfamilies. The method was extended to LC-MS for further characterization of the metabolites using standards and the probable metabolites were proposed.
\end{abstract}

Key words: RIS, Microsomes, Cytochrome P450, Biotransformation, LC-MS.

\section{INTRODUCTION}

Risperidone (RIS) belongs to a class of benzisoxazole derivatives and chemically it is 3[2-[4-(6-fluoro-1, 2-benzisoxazol-3-yl)1-piperidinyl] ethyl] - 6, 7, 8, 9-tetrahydro2-methyl-4H-pyrido [1,2a] pyrimidin-4-one with molecular formula $\mathrm{C}_{23} \mathrm{H}_{27} \mathrm{~F} \quad \mathrm{~N}_{4} \mathrm{O}_{2}$ (molecular weight 410.5). ${ }^{1-2}$ Its structure is given in Figure 1.

An oral formulation of RIS has been approved in 1993 by US FDA for the treatment of schizophrenia. RIS is an atypical antipsychotic drug reported to improve both the positive and negative symptoms of schizophrenia. Its biotransformation study was examined using isolated microsomes, which is a rich source of drug metabolizing enzyme cytochrome P450 (CYP450). CYP450 superfamily is a large and diverse group of enzymes. It constitutes a large family of cysteinato-heme enzymes, present in all forms of life (plants, bacteria and mammals) and plays a key role in the oxidative transformation.

RIS is mainly metabolized by two metabolic pathways: (1) alicyclic hydroxylation and (2) oxidative N-dealkylation. 9-HydroxyRIS is also the most abundant metabolite in the plasma of rats, $\operatorname{dogs}{ }^{3}$ and humans. ${ }^{4}$ In vitro metabolism study using a panel of human liver microsomes showed that CYP2D6 and CYP3A4 are involved in the formation of 9 hydoxy RIS. ${ }^{5}$ Enantioselective 9 hydroxylation findings suggest that CYP2D6 plays a predominant role in $(+)-9$ hydroxylation of RIS whereas CYP3A catalyzes the formation of (-) - 9 hydroxymetabolite. ${ }^{6}$

In the present study, we have used more economical, efficient and feasible method
Submission Date: 07-07-2018; Revision Date: 31-10-2018; Accepted Date: 22-01-2019.

DOI: 10.5530/ijper.53.2s.64 Correspondence:

Ms. Prutha Shirodkar, Department of Pharmaceutical Chemistry, S.M.B.T. College of Pharmacy, Nashik, Maharashtra- 422403 INDIA.

Phone: $+91-7720072314$ E-mail: shirodkarprutha@ gmail.com

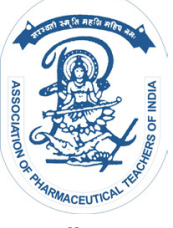

www.ijper.org 


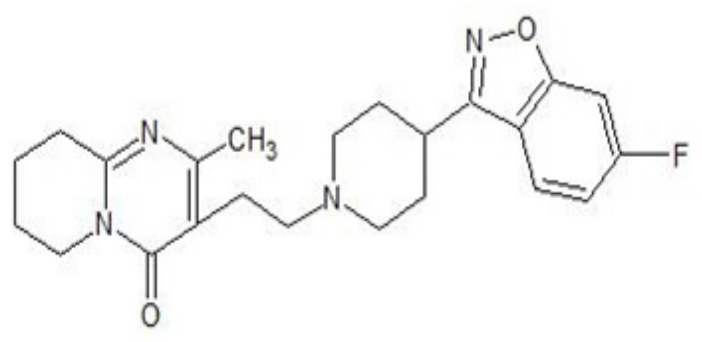

Figure 1: Structure of Risperidone (RIS).

for microsomal isolation. The conventional method for the isolation of liver microsomes as a source of drug metabolizing enzymes (mainly CYP450), from the animal livers, involves different centrifugation technique. ${ }^{7}$ In vitro metabolism of RIS was investigated using the CYP450 enzymes by calcium aggregation method. This method has been applied for the isolation of microsomes from rat liver and thus evaluates the utility of calcium precipitate method for isolation of microsomes for routine drug metabolism studies. ${ }^{8}$

More specifically, the project aimed at the development of protocol and in vitro assays to study metabolism of RIS in prepared rat liver microsomes. Standardization experiments were carried out for the enzyme for optimizing the incubation conditions (protein concentration, incubation time, substrate concentration determination). The final approach of the present study was to identify different metabolites of RIS in vitro and to better characterize the biotransformation study.

\section{MATERIALS AND METHODS}

\section{Chemicals and reagents}

All chemicals and solvents used in the investigation were of analytical grade purchased from S.D. Fine Chemicals, Mumbai, India. NADPH (nicotinamide adenine dinucleotide phosphate), was purchased from Sigma, India. Analytically pure samples of RIS (purity $>99 \%$ ) and 9-hydroxy RIS (9-OH-RIS) (purity $>99 \%$ ) were procured as gift samples from a reputed pharmaceutical company in India.

\section{Preparation of rat liver microsomes}

Male Wistar rats (250-300 g) $(n=4)$ used were not subjected to any form of treatment/ medication prior to this study. Guidelines of Committee for the Purpose of Control and Supervision on Experiments on Animals (CPCSEA), Government of India, were followed. The in- house Animal Ethics Committee approved all experimental procedures.

The method of Schenkman and Cinti with minor modifications was used for isolation of microsomes. ${ }^{9-10}$ The entire procedure was carried out at $0-4^{\circ} \mathrm{C}$ temperature in an ice bath. The excised livers $(20 \mathrm{~g}$ per batch and 4 such batches) were thawed, finely chopped with a pair of scissors and the excised liver was homogenized using four times $(40 \mathrm{ml})$ the weight of the liver of 10 $\mathrm{mM}$ Tris- $\mathrm{HCl}$ buffer containing $0.25 \mathrm{M}$ sucrose, $\mathrm{pH} 7.4$ in a Potter glass homogenizer equipped with Teflon pestle. The homogenate was subjected to centrifugation at $13,000 \mathrm{x} \mathrm{g}$ in a refrigerated centrifuge for $10 \mathrm{~min}$ at $4^{\circ} \mathrm{C}$ and the precipitate was discarded. The supernatant was maintained at $4^{\circ} \mathrm{C}$ and solid calcium chloride was added to the supernatant to yield a final concentration of $10 \mathrm{mM}$. The solution was continuously stirred for 30 min with a glass rod and then centrifuged at $25,000 \times \mathrm{g}$ for $10 \mathrm{~min}$ at $4^{\circ} \mathrm{C}$. The firmly packed pellets of microsomes thus obtained were resuspended by homogenization in $100 \mathrm{mM}$ tris- $\mathrm{HCl}$ buffer containing $20 \% \mathrm{w} / \mathrm{v}$ glycerol and $10 \mathrm{mM}$ EDTA (ethylenediaminetetraacetic acid), $\mathrm{pH} 7.4$ in a volume equivalent to the weight of the liver and stored at $-70^{\circ} \mathrm{C}$ till further use. The microsomes obtained were further characterized by determining their protein and CYP450 content.

\section{Determination of protein content of microsomes by Biuret method ${ }^{11}$}

$100 \mathrm{mg} / \mathrm{ml}$ stock solution of bovine serum albumin (BSA) was prepared in $0.1 \mathrm{M}$ sodium phosphate buffer ( $\mathrm{pH}$ 7.4). A series of dilutions of BSA ranging from $20 \mathrm{mg} / \mathrm{ml}$ to $60 \mathrm{mg} / \mathrm{ml}$ were prepared from a $100 \mathrm{mg} / \mathrm{ml}$ stock solution of BSA for generation of a calibration curve. The absorbance was read at $540 \mathrm{~nm}$ UV spectrophotometer. The protein concentration of the rat liver microsomes was obtained by interpolation using the equation obtained after linear regression.

\section{Determination of cytochrome content of microsomes by Omura and Sato Method ${ }^{12-13}$}

Microsomes were added to $0.1 \mathrm{M}$ potassium phosphate buffer $\mathrm{pH}, 7.4$ containing $0.5 \% \mathrm{~W} / \mathrm{V}$ Triton X100 and $1 \mathrm{mM}$ EDTA, in a test tube and diluted in the ratio 1:9. This solution was stirred thoroughly and divided into two $3 \mathrm{ml}$ quartz cuvettes. Both the cuvettes containing microsomal preparations were saturated with 30 to 40 bubbles of carbon monoxide (CO) gas for $45 \mathrm{sec}$ at the rate of 1 bubble/s. Sodium dithionite was added only to the sample cuvette and mixed properly. The sample was scanned from $400-500 \mathrm{~nm}$ to obtain a reduced CO $\mathrm{v} / \mathrm{s}$ oxidized $\mathrm{CO}$ difference spectrum. An extinction coefficient of $106 \mathrm{mM}^{-1} \mathrm{~cm}^{-1}$ was used for the determination of CYP450 content. 


\section{Microsomal incubations}

Microsomal incubations were performed with the isolated liver microsomes of rat liver. Incubations were performed in phosphate buffer $\mathrm{pH}$ 7.4. Incubations were carried out in micro centrifuge tube at stated conditions. Briefly, the incubations were conducted in a total volume of $1 \mathrm{ml}$ of $0.1 \mathrm{M}$ sodium phosphate buffer containing $0.001 \mathrm{M}$ EDTA, pH 7.4 and 50 or $100 \mu \mathrm{l}$ microsomes, ${ }^{8}$ substrate at a final concentration of 100 and $200 \mu \mathrm{M}$. Incubations were initiated with $6 \mathrm{mM} \mathrm{NADPH},{ }^{14}$ and were performed at $37^{\circ} \mathrm{C}$ for $5,10,20,60$ and $90 \mathrm{~min}$. After incubation, the reactions were stopped with $500 \mu \mathrm{l}$ of $0.5 \mathrm{M} \mathrm{NaOH}$. Control incubations were also performed either without microsomes or without RIS, in order to evaluate the possible interference from incubation components. All the samples were stored in deep freezer $\left(-70^{\circ} \mathrm{C}\right)$ till further extraction and HPLC analysis.

\section{Sample preparation for HPLC analysis}

Samples were extracted using $(4 \mathrm{ml})$ dichloromethane. ${ }^{15}$ Both the aqueous and organic layers were allowed to separate. The organic layer was evaporated to dryness at $45^{\circ} \mathrm{C}$ on a water bath for nearly about $2-3 \mathrm{~h}$. The residue was reconstituted in $500 \mathrm{ml}$ of mobile phase. After extraction, clear supernatants were injected to HPLC analysis.

\section{Optimized HPLC conditions}

The analysis of drug was carried out on a JASCO HPLC system equipped with a quaternary gradient pump (model JASCO, PU-2089 plus), a $20 \mu$ injection loop (Rheodyne 7725i) and a UV-Vis (UV-2075 plus) detector. The chromatograms were analyzed using Chrompass software (version 1.8.6.1). RIS and its metabolites were separated with a reverse phase HiQ Sil $\mathrm{C}^{18} \mathrm{HS}$ column $(250 \mathrm{~mm} \times 4.6 \mathrm{~mm} \times 5 \mu \mathrm{m})$. The mobile phase consisted of methanol-potassium dihydrogen phosphate ( $\mathrm{pH} 5.4$, $50 \mathrm{mM})(50: 50, \% \mathrm{v} / \mathrm{v}){ }^{6,16}$ The analytes were eluted at a flow rate of $1.0 \mathrm{ml} / \mathrm{min}$. Run time was kept at $14 \mathrm{~min}$ and absorbance was monitored at $280 \mathrm{~nm}$. Metabolites were identified by comparison of Retention times (RT) and co-injection of standards (spiking the metabolite mixture with authentic standards). The proposed method was validated by determining linearity, precision, accuracy and specificity of $5-100 \mu \mathrm{g} / \mathrm{ml}$ RIS as per ICH guidelines. ${ }^{17-18}$

\section{LC-MS Instrumentation}

Identification of biotransformation products by LC-MS technology was developed. Chromatographic separation was carried out on an Agilent Technologies 1200 series
LC system equipped with a column Agilent Eclipse C18 column $(4.2 \mathrm{~mm}$ id $\times 150 \mathrm{~mm}, 5 \mu)$. A mobile phase consisting A: methanol-ammonium formate buffer $(5 \mathrm{mM})(80: 20, \% \mathrm{v} / \mathrm{v})$ and B: methanol- ammonium formate buffer $(5 \mathrm{mM})(90: 10, \% \mathrm{v} / \mathrm{v})$ used at a gradient condition \% B time (min): 10/0.1, 10/0.3, 90/15.0, 90/17.0, 10/17.1, 10/20. ${ }^{19}$ Flow rate was maintained at $0.5 \mathrm{ml} / \mathrm{min}$. The mobile phase was filtered by passing through a $0.22 \mu \mathrm{m}$ membrane filter and degassed on sonicator. Sample injection volume was $10 \mu \mathrm{l}$. The flow rate was maintained at $0.7 \mathrm{ml} / \mathrm{min}$. A liquid chromatography coupled with a mass spectrometer of Agilent technology with triple quadropole mass analyser 6460, operated using electrospray ionization (ESI) source in positive mode..$^{20}$ Analysis was performed in selected ion monitoring (SIM) mode. It was chosen for identification of interested compound. Following parameters were set: capillary voltage: $3500 \mathrm{~V}$, nebulizer pressure: 40 psi, nebulizer voltage: $500 \mathrm{~V}$, Sheath gas temperature: $360^{\circ} \mathrm{C}$, sheath gas flow: $10 \mathrm{l} / \mathrm{min}$, gas temperature: $350^{\circ} \mathrm{C}$ with a gas flow: $8 \mathrm{l} / \mathrm{min}$. The peak area of transition from $\mathrm{m} / \mathrm{z}$ 411.2, $[\mathrm{M}+\mathrm{H}]^{+}$to a product ion $191.3 \mathrm{~m} / \mathrm{z}$, with collision energy of $10 \mathrm{eV}$ and fragmentor energy of 100 was used. Instrument control, data acquisition and data processing were carried out with the Mass hunter software. RIS and paliperidone stock solutions were prepared in acetonitrile $(1.0 \mu \mathrm{g} / \mathrm{ml})^{21}$ and stored at $-14^{\circ} \mathrm{C}$ to maintain good stability of them.

\section{RESULTS}

\section{Validation}

The validation data demonstrates good precision and accuracy, which proves the reliability of the proposed method. The proposed method is advantageous for quantification in tablet dosage form, bulk drugs as well as for analyzing routine quality control samples of RIS. The details of various validation parameters in brief are as shown in Table 1.

\section{Determination of protein content of microsomes by Biuret method}

The standard curve was prepared by plotting the absorbance values versus concentration of BSA ranging from $20 \mathrm{mg} / \mathrm{ml}$ to $60 \mathrm{mg} / \mathrm{ml}$ as shown in Figure 2 . The protein concentration of the rat liver microsomes was obtained by interpolation using the equation $y=0.0067 x+0.0038$. The protein concentration of RLM sample was found to be $43.5 \mathrm{mg} / \mathrm{ml}$.

\section{Spectral CYP450 content of liver microsomes}

CYP content of rat liver microsomes was found to be 9.00 and $9.90 \mathrm{nM} / \mathrm{ml}$, which indicates presence of $\mathrm{P} 450$, 


\begin{tabular}{|c|c|c|}
\hline \multicolumn{2}{|c|}{ Table 1: Summary of Validation Parameters of RIS by } \\
RP-HPLC.
\end{tabular}

$\mu \mathrm{g}$ : Microgram; LOD: Limit of Detection; LOQ: Limit of Quantification; RSD: Relative Standard Deviation; NMT: Not More Than; \%: Percentage

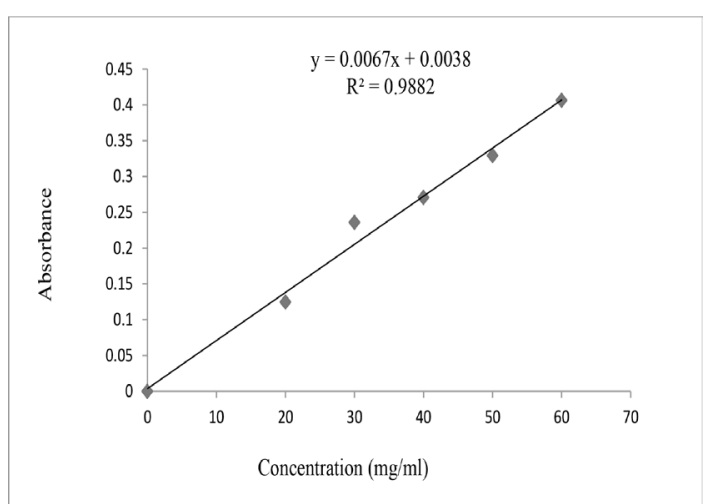

Figure 2: Absorbance versus concentration $(\mathrm{mg} / \mathrm{ml})$ of BSA.

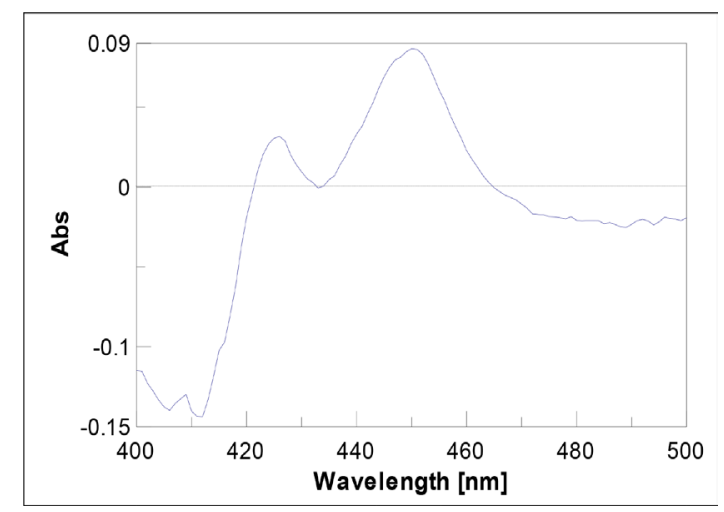

Figure 3: Carbon monoxide difference spectra showing absorption maxima at $450 \mathrm{~nm}$.

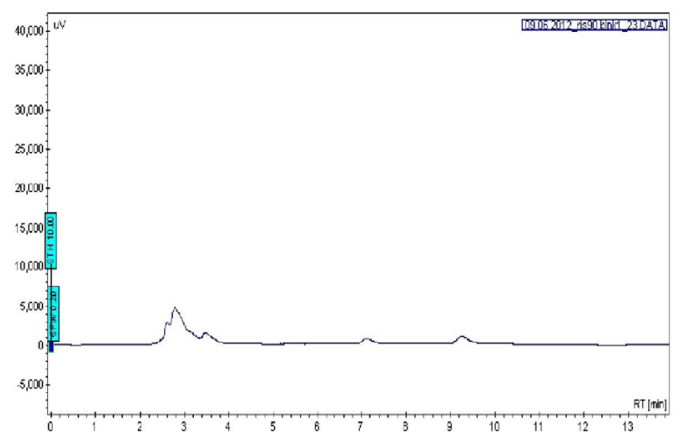

(A)

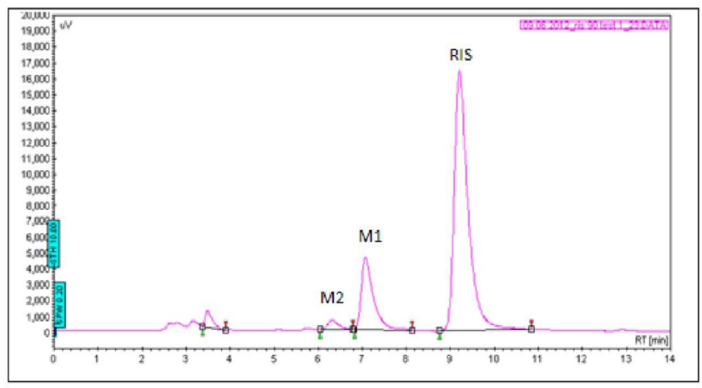

(B)

Figure 4: (A) HPLC-UV chromatogram representing blank microsomal sample without substrate; (B) HPLC-UV chromatogram representing microsomal incubation test sample.

the microsomal CO-binding pigment as shown in Figure 3.

\section{HPLC method evaluation}

For HPLC method development and standardization assay, the samples were prepared as per the stated incubation conditions. Standard RIS and paliperidone eluted at 9.2 and $7.0 \mathrm{~min}$ respectively, under the stated HPLC conditions. When microsomal incubations were spiked, all metabolites identified on the basis of their RTs, co-chromatographed with their corresponding authentic standard. The unchanged RIS was eluted at $9.2 \mathrm{~min}$. The metabolites M1 and M2 were eluted at 7.0 and 6.28 min respectively. A chromatogram representing blank microsomal sample (without substrate) and microsomal incubation sample are shown in Figure 4.

\section{LC-MS method development}

The extracted sample was further analysed for metabolite identification by LC-MS technique. Total ions chromatograms of the test incubation, showed three peaks at RT 11.47, 12.31 and $13.41 \mathrm{~min}$ for M2, M1 and RIS respectively. The RIS has $\mathrm{m} / \mathrm{z}$ value of 411.1 in standard and incubation sample under same LC/MS conditions. The standard paliperidone and M1 from incubation mixture showed $\mathrm{m} / \mathrm{z}$ value of 427.1 having same RT 12.13 min shown in Figure 5- (A), (B), (C-i), (C-ii), (C-iii). 


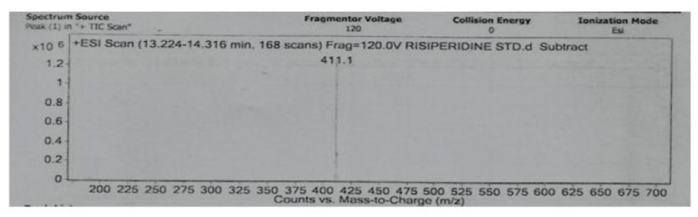

(A)

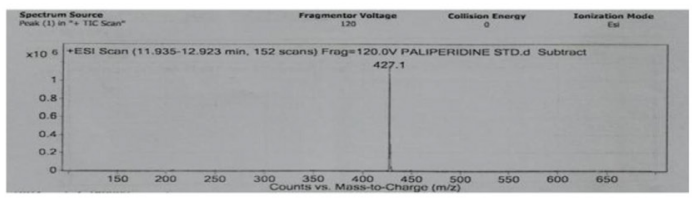

(B)

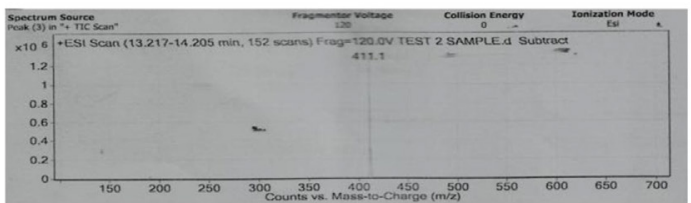

$(\mathrm{C}-\mathrm{i})$

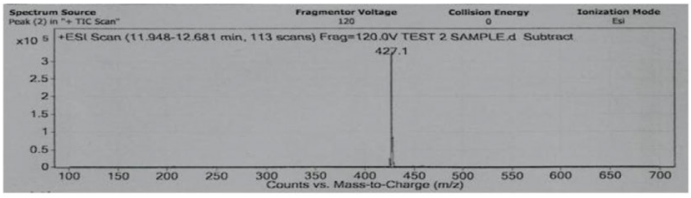

(C-ii)

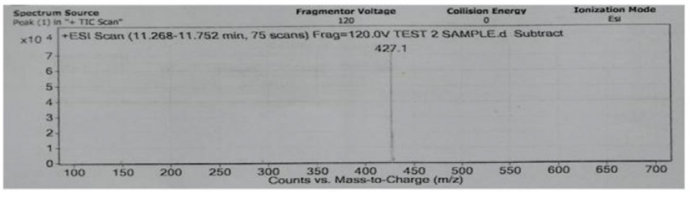

(C-iii)

Figure 5: (A) +ESI-MS spectra of standard RIS, (B) +ESI -MS spectra of standard paliperidone $(\mathrm{C}-\mathrm{i}, \mathrm{ii}, \mathrm{iii})+\mathrm{ESI}-\mathrm{MS}$ spectra of microsomal test sample.

\section{DISCUSSION}

In vivo metabolism of RIS $^{3-4}$ report have used the radiolabeled drugs because of which minute amount of all the metabolites formed by different metabolic pathways were detected. Major metabolic pathways of RIS in rats and dogs were the same as those in humans. The main pathway was the hydroxylation at the alicyclic part of the 6,7,8,9-tetrahydro-2-methyl-4H-pyrido $[1,2-a]$ pyrimidin-4-one moiety. The 9-OH-RIS was the main metabolite in dogs as well as in humans, whereas 7-hydroxy-RIS (7-OH-RIS) accounted for a few percent of the dose. In rats, the metabolism was more extensive, resulting in dihydroxy-RIS and hydroxy-keto-RIS. Other major metabolic pathways were the oxidative dealkylation at the piperidine nitrogen and the scission of the isoxazole in the benzisoxazole ring system. In vitro study using human liver microsomes showed the formation of only one metabolite 9-hydroxy-RIS which is highly correlated with CYP2D6 and 3A activities. ${ }^{5}$ In the present study, two metabolites of RIS were detected in the rat liver microsomal incubation in vitro. As shown in the LC-MS data, standard RIS has $\mathrm{m} / \mathrm{z}$ value of 411.1, at RT 13.41 min indicate the unchanged RIS in the incubation sample under same LC/MS conditions. The standard paliperidone and M1 from incubation mixture showed $\mathrm{m} / \mathrm{z}$ value of 427.1 having same RT (12.13 $\mathrm{min})$. Since the difference in $\mathrm{m} / \mathrm{z}$ value is $16 \mathrm{amu}$ between M1 and RIS, indicating hydroxylation reaction. Thus, the M1 peak can be confirmed as a peak of paliperidone (9-hydroxylated metabolite of RIS). Also, the $\mathrm{m} / \mathrm{z}$ value of M2 peak was found to be 427.1 and from the difference in the $\mathrm{m} / \mathrm{z}$ value $(16 \mathrm{amu})$ indicate that both the metabolites are hydroxylated metabolite. However, the RT of M1 and M2 are different, which indicate difference in the position of hydroxylation. So the probable M2 metabolites can be 6 or 7 or 8 hydroxy RIS. However, reports suggest as we discussed earlier, that the hydroxylation is predominantly occurring at $7^{\text {th }}$ position of 6,7,8,9-tetrahydro-2-methyl-4H-pyrido [1, 2-a] pyrimidin-4-one moiety, ring of RIS. Therefore, the metabolite (M2) was possibly found to be 7-hydroxyRIS. The RP-HPLC and LC-MS data are shown in Table 2. In rats, just as in humans, alicyclic hydroxylation occurred predominantly at the 9-position of the tetrahydropyridopyrimidinone moiety. ${ }^{4}$ The resulting 9-OH-RIS was by far the main metabolite, accounting for the largest percent $(10.8 \%)$ than any other metabolite, whereas 7-OH-RIS was only a minor metabolite, accounting for a few percent $(1.7 \%)$ as given in Figure 6.

Table 2: RP-HPLC and LC-MS data of test sample.

\begin{tabular}{|c|c|c|c|c|}
\hline $\begin{array}{c}\text { Sr. } \\
\text { No. }\end{array}$ & $\begin{array}{c}\text { RP-HPLC } \\
\text { RT (Min) }\end{array}$ & $\begin{array}{c}\text { LC-MS } \\
\text { RT (Min) }\end{array}$ & $\begin{array}{c}\mathbf{m} / \mathbf{z} \\
\text { ratio }\end{array}$ & $\begin{array}{c}\text { Name and } \\
\text { structure }\end{array}$ \\
\hline 1 & 9.2 & 13.41 & 411.1 & RIS \\
\hline 2 & 7.0 & 12.13 & 427.1 & 9-OH RIS \\
\hline 3 & 6.28 & 11.47 & 427.1 & 7-OH RIS \\
\hline
\end{tabular}

RT: RT; Min: Minutes
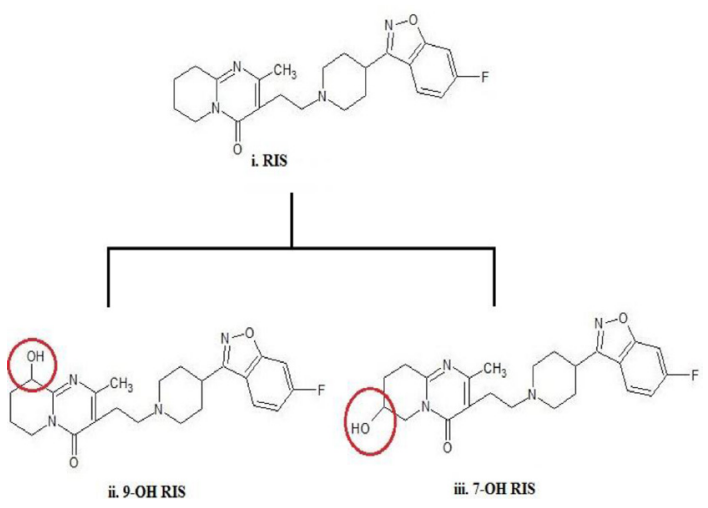

Figure 6: Alicyclic hydroxylation of RIS i. Risperidone, ii. 9-Hydroxy Risperidone, iii. 7-Hydroxy Risperidone. 
Table 3: Metabolites (M1 and M2) formation with time.

\begin{tabular}{|c|c|c|}
\hline Time $(\mathbf{m i n})$ & \% of 9-OH RIS & \% of 7-OH RIS \\
\hline 5 & 4.4 & - \\
\hline 10 & 8.7 & - \\
\hline 20 & 13.6 & - \\
\hline 60 & 16.8 & 1.6 \\
\hline 90 & 16.7 & 1.7 \\
\hline
\end{tabular}

$\%$ : Percentage

Min: Minutes

The percentage of both the metabolites (M1, M2) formed is given in Table 3 .

\section{CONCLUSION}

In present study, in vitro metabolism of RIS was studied. Metabolism of RIS in rat was found to be similar to the humans and dogs. Metabolism of RIS majorly occurs through hydroxylation at the alicyclic part of the 6,7 , 8, 9-tetrahydro-2-methyl-4H-pyrido [1, 2-a] pyrimidin4-one moiety. Two metabolites of RIS were detected in LC-MS study in the rat liver microsomal incubation in vitro i.e. 9-OH-RIS and 7-OH-RIS. Out of two metabolites 9-OH-RIS is major metabolite and 7-hydroxy metabolite is minor metabolite. The method employed for separation and detection is quite accurate and able to detect the metabolites.

\section{ACKNOWLEDGEMENT}

We would like to thank the management of Bombay College of Pharmacy, Kalina, Bombay, for their technical assistance. I am also grateful to Reliable Analytical lab, Thane and Anatek Services Pvt Ltd, Mumbai for providing me the necessary instruments.

\section{CONFLICT OF INTEREST}

The authors declare no conflict of interest.

\section{ABBREVIATIONS}

RIS: Risperidone; CYP450: Cytochrome-450; $\mu \mathrm{g}$ : microgram; ml: Mililiter, $\mu$ l: Microliter; ICH: International Council for Harmonisation; EDTA: Ethylene Diamine Tetracetic Acid; M: Molar; mM: Milimolar; nM: Nanomolar.

\section{REFERENCES}

1. Moffat AC, Osselton MD, Widdop B. Clarke's Analysis of Drugs and Poisons, $3^{\text {rd }}$ ed, Pharmaceutical Press London. 2004;2:1537.

2. USP- NF, The official compendia of standards, Authority of United States Pharmacopoeia Convention, USA. 2009;3:3516-8.

3. Meuldermans W, Hendrickx J, Mannens G, Lavrijsen K, Janssen C, Bracke $\mathrm{J}$, et al. The metabolism and excretion of risperidone after oral administration in rats and dogs. Drug Metab Dispos. 1993;22(1):129-38.

4. Mannens G, Huang ML, Meuldermans W, Hendrickx J, Woestenborghs R, Heykants J. Absorption, metabolism and excretion of risperidone in humans. Drug Metab Dispos. 1993;21(6):1134-41.

5. Fang J, Bourin M, Baker G. Metabolism of risperidone to 9-hydroxyrisperidone by human cytocromes P450 and 3A4. Naunyn- Schmiedeberg's Arch Pharmacol. 1993;359(5):47-151.

6. Furukori NY, Hidestrand M, Spina E, Facciola G, Scordo MG, Tybring G. Different enantioselective 9-hydroxylation of risperidone by the two human CYP2D6 and CYP3A4 enzymes. Drug Metab Dispos. 2001;29(10):1263-8.

7. Kamath SA, Rubin E. Interaction of calcium with microsomes: a modified method for the rapid isolation of rat liver microsomes. Biochem Biophys Res Commun. 1972;49(1):52-9.

8. Walawalkar $P$, Serai $P$, lyer K. Isolation and catalytic competence of different animal liver microsomal fractions prepared by calcium-aggregation method. Indian J Pharm Sci. 2006;68(2):262-5.

9. Schenkman JB, Cinti DL. A rapid method of preparation of liver microsomes (in vitro drug metabolism studies) by $\mathrm{Ca}^{+2}$ aided sedimentation method. Methods Enzymol. 1978;6:83-8.

10. Schenkman JB, Cinti DL. Hepatic mixed function oxidase activity in rapidly prepared microsomes. Life Sci. 1972;11(5):247-57.

11. Ninfa AJ, Ballou DP, Benore M. Quantification of protein concentration. Fundamental Laboratory Approaches for Biochemistry and Biotechnology, $1^{\text {st }}$ ed, John Wiley and Sons Inc England. 111.

12. Omura $\mathrm{T}$, Sato $\mathrm{R}$. The carbon monoxide-binding pigment of liver microsomes, evidence for its hemoprotein nature. J Biol Chem. 1964;239(7):2370-8.

13. Takashi M, Koike M. Quantitative determination of cytochrome P-450 in rat liver homogenate. Anal Bio Chem. 1976;75(2):596-603.

14. Subash S, Seervi M, lyer K, Damre A. Assessment of rat hepatic cytochrome $\mathrm{P}-450$ induction and inhibition potential of chlorogenic acid. Indian J Pharm Educ Res. 2011;45(1):32-9.

15. Moing JP, Edouard S, Levron JC. Determination of risperidone and 9-hydroxyrisperidone in human plasma by high-performance liquid chromatography with electrochemical detection. J Chromatogr. 1993;614(2):333-9.

16. Suthar AP, Dubey SA, Patel SR, Shah AM. Determination of risperidone and forced degradation behavior by HPLC in tablet dosage form. Int $\mathrm{J}$ Pharm Tech Res. 2009;1(3):568-74.

17. $\mathrm{ICH}$ guidelines. Q2B: Validation of analytical procedures: Methodology (CPMP/ICH/281/95): Geneva Switzerland. 1996.

18. $\mathrm{ICH}$ guidelines, Q2A: Validation of analytical procedures: Methodology (CPMP/ICH): Geneva Switzerland. 1994

19. Schneidera S, Sibill E, Yegles M, Neelsb H, Wenniga R, Muhe A. Time resolved analysis of risperidone and 9-hydroxy-risperidone in hair using $\mathrm{LC} /$ MS-MS. J Chromatogr B. 2009;877(24):2589-92.

20. Moody DE, Laycock JD, Huang W, Foltz RL. A High Performance Liquid Chromatography-atmospheric pressure chemical ionizationtandem mass spectrometric method for determination of risperidone and 9-hydroxyrisperidone in human plasma. J Anal Toxicol. 2004;28(6):494-7.

21. Huang M, Shentu J, Chen J, Liu J, Zhou H. Determination of risperidone in human plasma by HPLC-MS/MS and its application to a pharmacokinetic study in Chinese volunteers. J Zhejiang Univ Sci B. 2008;9(2):114-20. 
PICTORIAL ABSTRACT

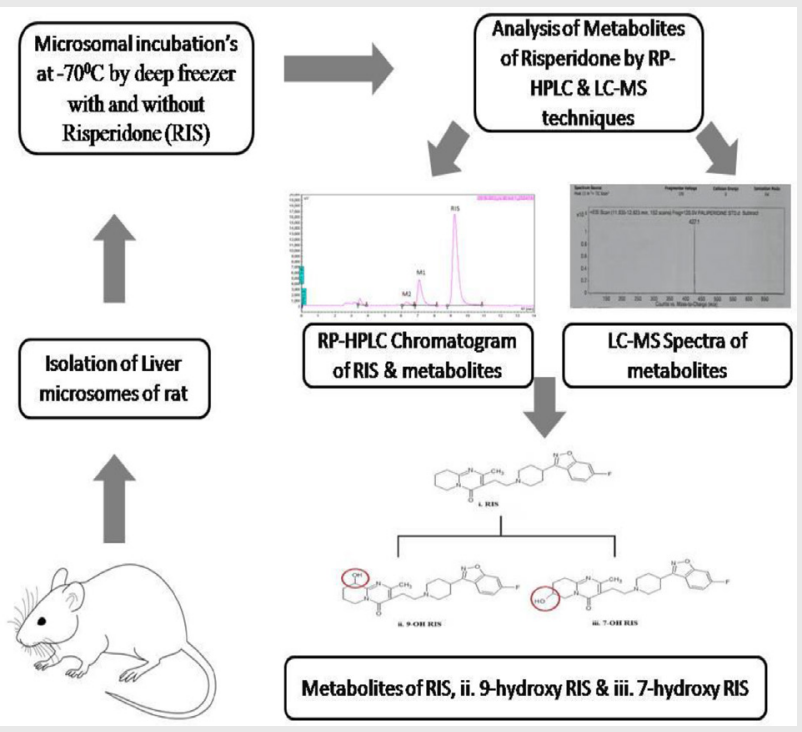

\section{About Author}

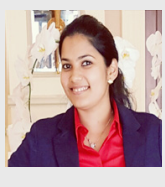

Prutha Shirodkar Pednekar, Currently working as a Regulatory Affairs Specialist in the company Mundipharma Middle East, based in Dubai, UAE. Handling registration for Pharma products in Middle East and Africa regions. Qualified as a Master of Pharmacy under Pune University.

\section{SUMMARY}

- Biotransformation study of RIS was examined using isolated microsomes from rat liver. The CYP450 enzymes were isolated from rat liver microsomes by calcium aggregation method. Determination of protein content and cytochrome content were carried out by Biuret method and Omura and Sato method respectively. Incubation of microsomes was carried out in phosphate buffer $\mathrm{pH} 7.4$ by using micro centrifuge tube. Extraction of the incubated microsomes was carried out in dichloromethane. All the extracted samples were analyzed first by RP-HPLC technique and metabolites were identified based on their RT. The resultant chromatographs were compared with the authenticstandard.Differentelution times were recorded in RP-HPLC method like for unchanged RIS was eluted at $9.2 \mathrm{~min}$. while, $\mathrm{M} 1$ and $\mathrm{M} 2$ metabolites were eluted at 7.0 and 6.28 min respectively. Three peaks at RT 11.47, 12.31 and 13.41 min were detected in LC-MS technique for M2, M1 and RIS respectively. Out of this three peaks, two metabolites of RIS were detected in LC-MS study in the rat liver microsomal incubation in vitro i.e. 9-OH-RIS and 7-OH-RIS. 9-OH-RIS is a major metabolite while 7-hydroxy metabolite is minor metabolite was found.

Cite this article: Shirodkar P, Chavan H, Mogal R, Dhake A. In vitro Metabolism of Risperidone on Isolated Microsomes of Rat Liver: Metabolite Identification and Profiling by RP-HPLC and LC-MS Techniques. Indian J of Pharmaceutical Education and Research. 2019;53(2S):s179-s185. 